\title{
Arbor
}

\section{La historia de los genes homeóticos}

\author{
Ginés Morata
}

Arbor CLXVIII, 662 (Febrero 2001), 229-246 pp.

\section{Origenes de la Biología del Desarrollo}

Desde el principio de la Cultura humana el hombre se ha interrogado sobre los hechos biológicos del desarrollo, seguramente porque era partícipe de muchos de ellos o los observaba en los animales domésticos. De hecho, la primera teoria biológica conocida pretendia explicar el desarrollo de los seres vivos. Se observaba que las hembras de nuestra especie, por algún procedimiento misterioso, son capaces de generar dentro de ellas a otro ser de la misma especie. Este hecho fascinante seguramente deberia de tener una explicación lógica y ya en los textos vedas se proponia la Teoria de la Sangre Menstrual. Esta hipótesis partia de la observación de que la preñez de las hembras de mamífero se correlacionaba con la desaparición del ciclo menstrual. Se proponia entonces que debido a la intervención del macho de la especie, el material biológico que de otra forma se perdia, se cristalizaba en el nuevo ser vivo. La teoria proponia que las hembras de la especie proveian de la materia prima mientras que el varón suministraba el fermento informacional. Esta teoria fue recogida por los pensadores griegos y de forma mas o menos sofisticada perduró hasta el siglo XVIII. De hecho, cuando Leuwenhoek inventó el microscopio y pudo examinar directamente el esperma humano llegó a ver un homúnculo preformado en el propio esperma. Este es uno de esos casos en los que el avance tecnológico no supuso un mejor conocimiento de la realidad sino mas bien soporte del error.

Durante muchos siglos la Biología del Desarrollo, como el resto de la Biología fue esencialmente una ciencia descriptiva. Los naturalistas se dedicaron a describir las diversas modificaciones que aparecen 


\section{Ginés Morata}

durante el desarrollo de las diversas especies; duración de las diversas fases embrionarias, tamaño de los embriones, etc.

Con el advenimiento de la Genética se puso de manifiesto el papel que tienen los genes en los procesos de desarrollo. A raiz del descubrimiento por Muller de la posibilidad de inducir mutaciones artificialmente por medio de rayos $\mathrm{X}$ y de agentes quimicos, se pudo sistematizar el efecto sobre el desarrollo de las diversas mutaciones. Esto dio lugar al nacimiento de la Genetica del Desarrollo.

En este punto conviene clarificar que se entiende por Genetica del Desarrollo. En un sentido trivial la gran mayoria de los genes estan involucrados en el proceso, ya que el $90 \%$ de las mutaciones son letales, esto es, son incompatibles con el desarrollo completo del individuo. Sin embargo, la gran mayoria de estas mutaciones lo son en genes imprescindibles para la correcta funcion celular. El concepto de Desarrollo está ligado a organismos multicelulares, que manifiestan diversos tipo de diferenciaciones celulares (células nerviosas, musculares, epidérmicas, etc) y que aparecen en posiciones fijas demtro de la estructura tridimensional del cuerpo. Asi pues, la Genética del Desarrollo se ocuparia esencialmente del control genético los procesos de Diferenciación y Morfogénesis. Durante los años 20 a 50 se encontraron y estudiaron gran cantidad de mutaciones, pero pocas de ellas estaban directamente relacionadas con procesos especificos de desarrollo. Entre estas se incluian un grupo especial que daban lugar a transformaciones de un órgano en otro. Aumque llamaron la atención por lo espectacular de su fenotipo, no se hizo un análisis sistemático hasta que Edward Lewis inició sus estudios en los llamados genes bithorax en los años 50 .

\section{El reduccionismo en Biología. El ADN es la fórmula básica}

El año 1953 marca, con el descubrimiento de la estructura del ácido desoxiribonucleico (ADN) por parte de Watson y Crick, el inicio de la Biología Molecular y con ella el comienzo de una nueva era en la biología. Esencialmente lo que Watson y Crick demostraron es que la información genética, esto es, la información necesaria para construir un ser vivo, sea este una bacteria, una mosca o un ser humano, está contenida en la estructura de una molécula concreta que tiene unas características químicas determinadas y que se puede aislar, estudiar y eventualmente modificar. El análisis experimental de los fenómenos biológicos más profundos, los procesos mediante los cuales se construyen 
y funcionan los seres vivos, quedó conceptualmente reducido al estudio de como se libera la información contnida en el ADN. Este enfoque reduccionista ha marcado la mentalidad de los investigadores en las últimas décadas y ha tenido una influencia muy profunda en la percepción actual de la Genetica del Desarrollo.

Un principio que emergió rápidamente de los primeros estudios moleculares es el de la Universalidad de los procesos biológicos fundamentales. El ADN es la molécula informacional de todos los seres vivos. Químicamente el $\mathrm{ADN}$ de una planta, un bacteria o un ser humano son indistinguibles. Además, el código genético, el procedimiento por el cual se traduce la información del $\mathrm{ADN}$ en proteínas, que son los componentes fundamentales de los seres vivos, es asimismo universal. E igualmente son generales muchos procesos celulares como el metabolismo energético, control de la división celular, mecanismos de transporte intracelular etc.

Sin embargo, la gran diversidad morfológica que presentan los animales multicelulares produce tal impresión de complejidad que hasta recientemente no se concebía que existieran leyes generales aplicables a todas las especies. Hay en la actualidad unos10 millones de especies animales, y han existido muchas más, que manifiestan una enorme variedad de formas, tamaños y ciclos vitales. Era difícil imaginar que debajo de esta gran variabilidad morfológica y funcional subyacen unos mecanismos unitarios comunes. $\mathrm{Y}$ sin embargo uno de los descubrimientos más fascinantes de la Biología de la última década es que estos mecanismos universales existen, aparecieron en el Cámbrico inferior, hace unos 540 millones de años y son los que generan la diversidad morfológica en el Reino Animal.

\section{Los organismos multicelulares. El principio de información posicional. Ensamblaje de las partes de un organismo}

El aspecto más destacable del diseño del cuerpo de los organismos multicelulares, un gusano, una mosca o un ser humano, es que estamos construidos en las tres dimensiones de espacio y que nuestra morfología particular resulta de la disposición espacial de los diversos órganos y tejidos unos con respecto a otros. La construcción del organismo tiene por consiguiente que integrar información sobre la posición relativa de las diversas partes a medida que estos se van generando.

Para construir un organismo tridimensional se necesita un tipo de información genética nueva que no está presente en un organismo 
unicelular. Aquí se trata no solamente de hacer funcionar la célula, replicar el ADN, expresarlo convenientemente, manufacturar las proteinas, etc.; hay que crear además tipos diferentes de celulas especializadas y órganos que se han de ensamblar en la posición adecuada en relación a los demas organos. Tiene por lo tanto que existir un tipo de información posicional, naturalmente codificado en el ADN, de forma que las diversas partes del organismo se ensamblen de forma adecuada unas respecto de otras.

El registro fosil indica que todos los grupos animales existentes en la actualidad aparecieron en un plazo de tiempo muy corto de unos 25 millones de años en el Cámbrico inferior, hace unos 540 millones de años. Es lo que se llama la «explosión del Cámbrico». Lo que la evolución inventó en el Cámbrico inferior fue el sistema genético por el que se genera la diversidad morfológica y el ensamblaje de los organismos multicelulares. La comprensión de este proceso de información posicional y su universalidad ha sido uno de los descubrimientos mas fascinantes de la Biología del final del siglo XX. Los resultados mas significativos se han obtenido en la mosca del vinagre Drosophila melanogaster, que es el objeto clásico de investigación en genética durante gran parte del siglo XX.

\section{Drosophila como organismo modelo para el estudio del desarrollo}

Drosophila es un insecto pequeño, de $1 \mathrm{~mm}$ de largo y aproximadamente un millón de células, que abunda en todo el mundo, con un ciclo biológico muy corto de 9-10 días, y que es muy fácil de cultivar en el laboratorio. Ha sido un modelo clásico de investigación en Genética durante el siglo XX y es con gran diferencia el organismo multicelular donde las tecnologías y métodos genéticos son más sofisticados. Perteneciente al grupo de los insectos holometábolos, Drosophila tiene un ciclo biológico complejo. El embrión se desarrolla dentro del huevo hasta formar la larva de primer estadio que emerge a las $22 \mathrm{hrs}$ (a $25^{\circ} \mathrm{C}$ ) de la fertilización. Durante este periodo no hay crecimiento en volumen, pero la célula inicial prolifera para formar todos los tejidos y órganos larvarios, formándose incluso los primordios de las estructuras del adulto. Como fuente de energía se utiliza el vitelo depositado en el huevo. La fase larvaria se caracteriza por crecimiento en volumen, tiene tres estadios y dura aproximadamente $96 \mathrm{hrs}$, al final de las cuales se inicia la metamorfosis, fase durante la cual la gran mayoría 
de los tejidos larvarios se histolizan y desaparecen, siendo sustituidos por los tejidos adultos. La metamórfosis dura 96 horas, emergiendo después el insecto adulto de la nueva generación.

Una característica importante de la organización del cuerpo de Drosophila es que es un organismo metamerizado. El cuerpo consiste en una cadena de segmentos o metámeros que se desarrollan de forma independiente unos de otros y que confieren la estructura segmentada caracteristica de los insectos . Esta organización metamerizada se establece ya en el embrión temprano, en el que ya se encuentran separadas las células que formarán cada segmento, el cual se desarrolla de forma particular tanto en sus aspectos externos como las estructuras internas, musculatura, sistema nervioso, etc.

Un primer problema que se planteó hace ya muchos años en Drosophila fue identificar el proceso genético responsable de la diversidad metamérica a lo largo del eje antero-posterior del cuerpo. Como se indica anteriormente ya se habia descrito un tipo muy especial de mutaciones, las llamadas mutaciones homeóticas, que transforman un órgano o un segmento en otro. Los ejemplos más notables son las mutaciones Antennapedia que transforman la antena en pata o Ultrabithorax que transforman el halterio en ala dando lugar a una mosca con cuatro alas. Claramente habia un elemento posicional involucrado, de forma que las células en la posición antena o halterio desarrollan estructuras normales, pero correspondientes a otra posición del cuerpo.

El descubrimiento de estas mutaciones tiene gran importancia teórica ya que indican la existencia de mecanismos de control general del desarrollo. En una mosca mutante con cuatro alas como la producida por la mutación Ultrabithorax de la figura 1 no se produce un desarrollo aberrante, ya que las alas adicionales que se forman en lugar del halterio son normales, lo que es anómalo es el sitio del cuerpo donde aparecen. La conclusión es que la función normal del gen seria reconocer la posición de células que han de formar el halterio y establecer en ellas el programa de desarrollo apropiado; en las moscas mutantes este grupo de células no es reconocido correctamente y adquieren un desarrollo inapropiado. Estas transformaciones sugieren que genes como Ultrabithorax son reguladores de alto rango que especifican (presumiblemente a través de otros genes subsidiarios) el desarrollo característico de un órgano o segmento. Un análisis más detallado de las diversas mutaciones homeóticas indica que todas ellas producen alteraciones de tipo segmental, transformando unos segmentos en otros siempre a lo largo del eje antero-posterior del cuerpo. La transformación 
afecta no solamente los elementos externos sino también todas las estructuras internas, sistema nervioso, musculatura, etc. Todo el desarrollo del segmento está modificado en la misma dirección. La implicación es que cada uno de estos genes controla el desarrollo de uno o varios de los segmentos de la mosca.

Es importante resaltar que este tipo de mutaciones no son una especialidad de Drosophila. Curiosamente, se descubrieron el siglo pasado en la especie humana como una serie de anomalías congénitas que transformaban unas vértebras en otras. El término homeosis alude precisamente a transformaciones de este tipo entre órganos homólogos. Como veremos más adelante, las anomalías encontradas en seres humanos muy probablemente reflejan una alteración genética similar a las encontradas en Drosophila.

\section{Número y disposición de los genes homeóticos de Drosophila. El complejo homeótico}

Dado el importante papel que tienen estos genes como reguladores generales del desarrollo, era muy importante saber cuántos de estos genes existen en el genoma de Drosophila. El fenotipo de las mutaciones individuales, que frecuentemente afectan solamente o mayormente a un único segmento sugería, y así fue aceptado durante mucho tiempo, que existía un gen por cada segmento. Esta idea fue propuesta en 1978 por Edward Lewis, el gran especialista en los genes bithorax, laureado con el premio Nobel en 1995. Se estimaba que habian de existir al menos 9 genes responsables del desarrollo del parte del torax y el abdomen.

Nuestro laboratorio contribuyó decisivamente a la solución de este problema en los años ochenta, aunque planteando una hipótesis radicalmente distinta a la de Lewis. El análisis genético llevado a cabo fundamentalmente por Ernesto Sánchez-Herero, demostró que había muchos menos genes homeóticos de los que se creía. Los 9 segmentos que forman la mitad posterior del torax y el abdomen entero se especifican con solamente tres genes, cada uno de estos genes controlaría el desarrollo no de un segmento sino de un grupo de ellos. Análisis posteriores tanto genéticos como moleculares corroboraron el modelo de varios segmentos por gen. Los últimos resultados han establecido que el conjunto de genes homeoticos primarios, el llamado complejo Hox, consiste en nueve genes que dan cuenta del desarrollo de los segmentos cefálicos, torácicos y abdominales (Figura 2). 


\section{La historia de los genes homeóticos}

FIGURA 1

Panel superior. Parte anterior de una mosca normal y una mutante para Antennapedia. Una flecha señala la posición de la antena normal y la transformada en pata de la mosca mutante.

Panel inferior. Comparación de una mosca normal (A, wt) con una mutante para el gen Ultrabithorax. La mosca normal posee un par de alas en el segundo

segmento torácico y un par de halterios o balancines en el tercer segmento torácico. En la mosca mutante los balancines están transformados en alas.
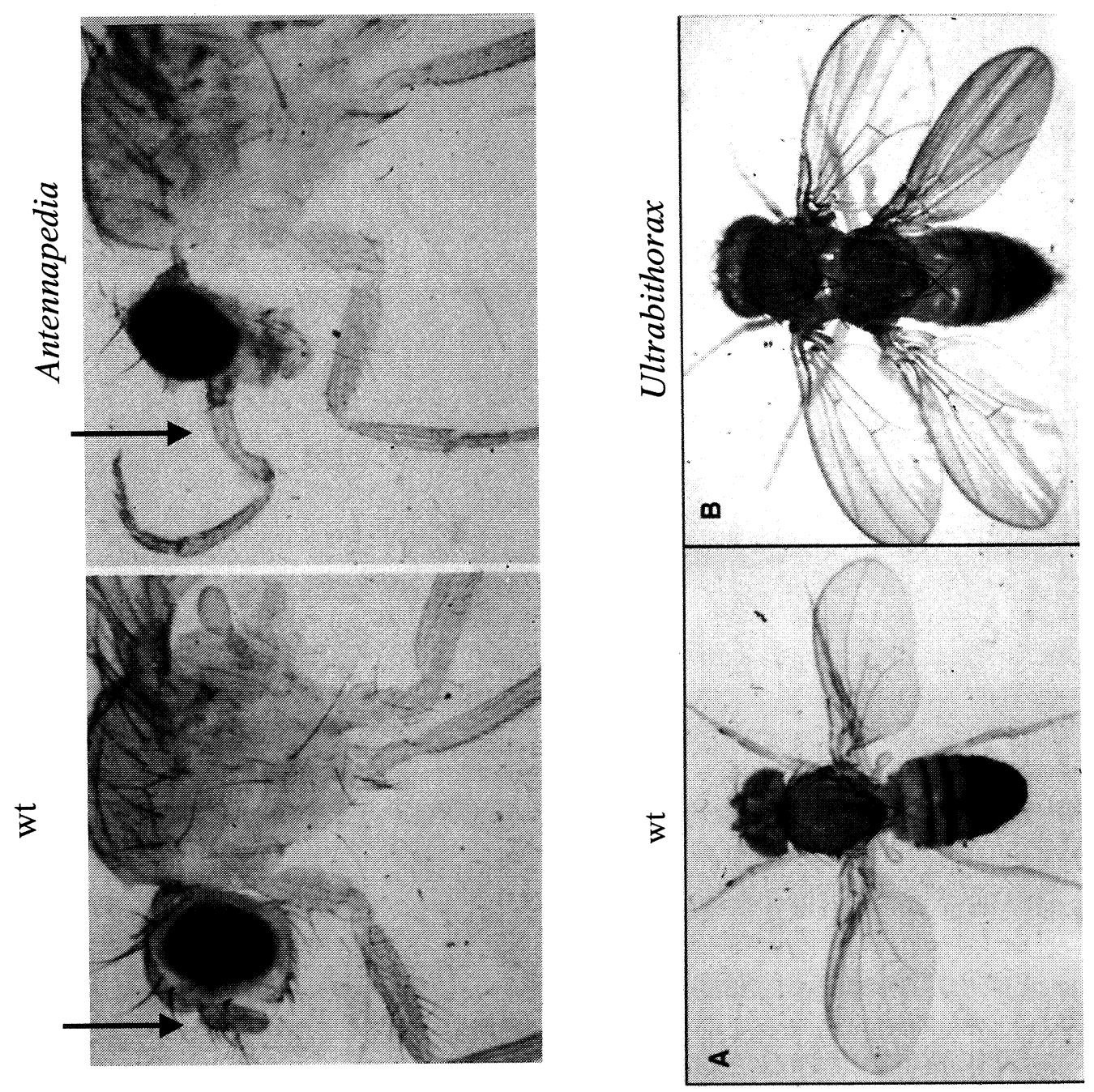
FIGURA 2

El conjunto del los genes del complejo Hox y la parte del cuerpo donde actuan. Todos los genes ANT, labial (lab), proboscipedia ( $p b$ ), Deformed (Dfd), Sex combs reduced (Scr) y Antennapedia (Antp), se representan en verde. Las flechas indican la parte del cuerpo que controlan varios de ellos. Los genes BX Ultrabithorax (Ubx), abdominal-A ( $a b d-A)$ y Abdominal-B ( $A b d-B$ ) se identifican según codigo de colores. Las flechas indican la parte del cuerpo cuyo desarrollo especifican. Por último, caudal (cad) especifica la region anal.

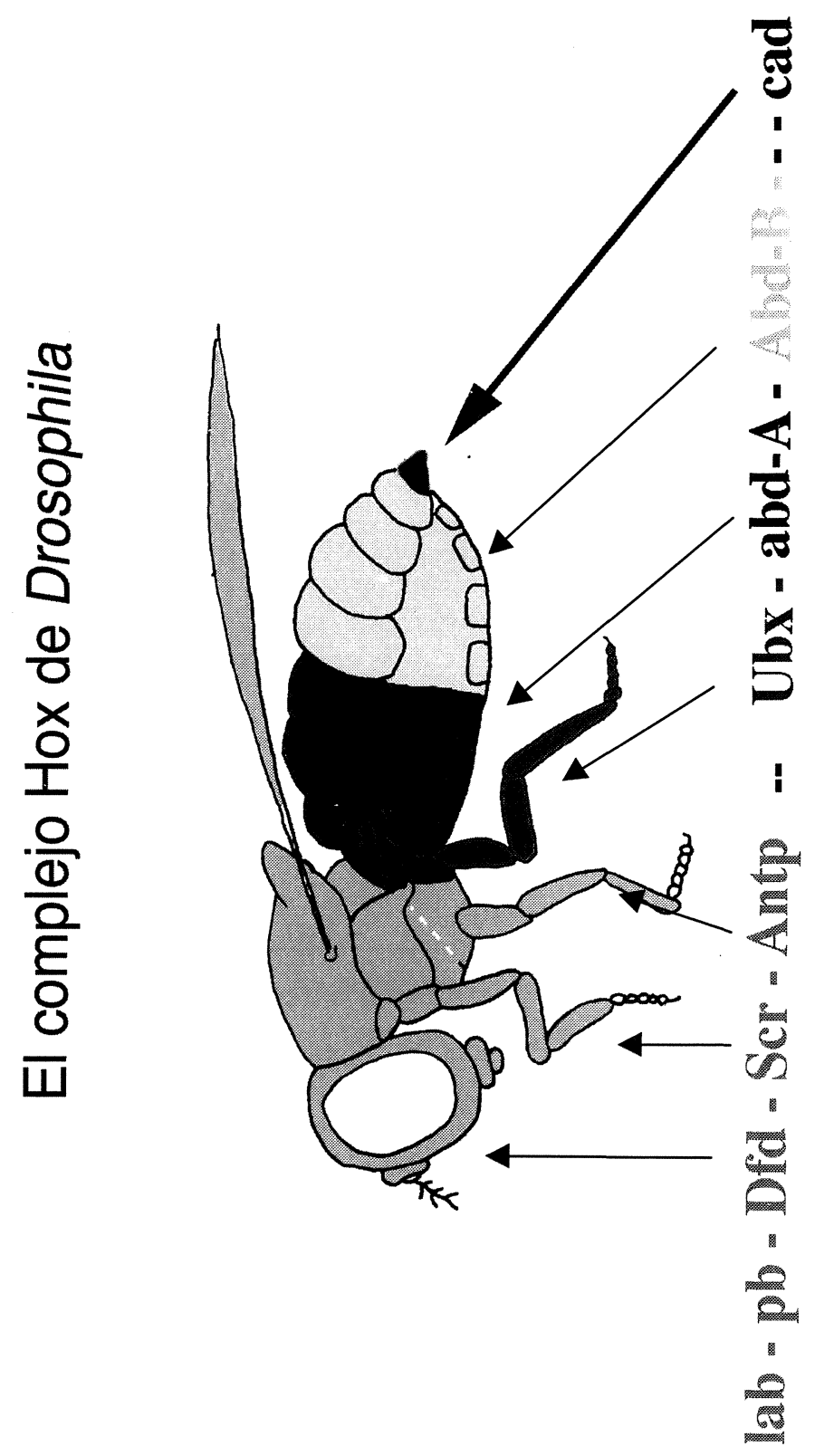


Una observación muy importante es que estos genes no están distribuidos al azar en los cromosomas, sino que forman dos grupos, tres genes del subcomplejo BX están adyacentes, mientras que los cinco del subcomplejo ANT forman un grupo aparte. Este hecho es muy significativo ya que sugiere que derivan de un gen ancestral por duplicación. Además, los genes BX tienen una estructura de doblete en los cromosomas politénicos de las glándulas salivares. Esta estructura también es indicio de duplicación, como habia sugerido Lewis. Posteriormente se observó que en otras especies de insectos como el coleóptero Tribolium y en otros lepidópteros y dípteros los complejos ANT y BX están juntos, abundando en la idea de un origen común para todos los homeóticos. Se ha visto que la regla general es que todos los genes homeóticos están agrupados en todas las especies en que se ha podido determinar su localización cromosómica. Puesto que están agrupados y tienen una evidente relación funcional y evolutiva, al conjunto se le denomina complejo homeótico o complejo Hox.

\section{Función del complejo Hox}

El análisis de la función de los genes Hox se ha estudiado mediante la inducción de combinaciones mutantes que eliminan la actividad de uno o varios genes homeóticos. Del fenotipo de la mutación se puede deducir en muchos casos la función normal del gen. De esta forma se ha visto que los genes del complejo ANT tienen su función primordial en la región cefálica y anterior del tórax, mientras que los genes BX controlan el desarrollo de parte del tórax y del abdomen. Existe la dificultad de que la mayoría de estas mutaciones son letales, por lo que no se puede estudiar el fenotipo en individuos adultos. Sin embargo, todas ellas permiten el desarrollo de la larva de primer estadio por lo que es posible estudiar el efecto de estas mutaciones en los segmentos larvarios. Se observa que en larvas deficientes para los genes Hox todos los segmentos se desarrollan de la misma forma, con el patrón característico de un segmento torácico, es decir, toda la diversidad morfológica del cuerpo desaparece. La funcion de estos genes es pues la de generar la diversidad morfológica en el eje anteroposterior.

El mecanismo de acción de estos genes no se conocía cuando se describió el fenotipo de las mutaciones, pero el efecto tan dramático de transformar un segmento en otro no podía ser evidentemente la función de un único gen. Se propuso que los genes homeóticos realizarían su función activando y/o reprimiendo baterías de genes subsidiarios, 
que serían responsables de cada uno de los aspectos particulares del desarrollo de cada segmento.

\section{Biología molecular de los genes homeóticos}

Aunque para comienzo de los años ochenta el análisis funcional de estos genes estaba ya muy elaborado, se sabia muy poco de la base molecular de su función. La nueva era en la Biología del Desarrollo se inició cuando el grupo de Hogness en Stanford clonó el primer gen homeótico, el gen Ultrabithorax. Inmediatamente se clonaron otros genes homeóticos como Antennapedia, abdominal-A y Abdominal-B y a continuación el resto. Esto permitió un análisis muy detallado de la estructura íntima y averiguar la naturaleza de los productos génicos de los genes Hox.

La primera sorpresa surgió muy pronto, durante los años 1984-85, cuando se observó por los grupos de Walter Gehring y Matt Scott que varios de los genes homeóticos clonados tenían secuencias en común. En concreto, todos tenían una secuencia de 180 pares de bases, que se llamó homeobox. Se demostró que la homeobox codifica para un polipéptido básico de 60 aminoácidos, el homeodominio, que es capaz de unirse al DNA. El análisis estructural indicó que el homeodominio tiene la clásica estructura hélice/vuelta/hélice que presentan varias proteínas con afinidad a ADN de levaduras y de bacterias. Aunque todos los genes del complejo Hox contienen una homeobox, estas no son exactamente idénticas, hay pequeñas diferencias entre ellas, que las hacen características de cada gen homeótico.

El hecho de que todos los genes homeóticos tuvieran la secuencia homeobox tiene dos implicaciones teóricas de gran importancia. 1) Las características físicas y estructurales del homeodominio como un motivo capaz de unirse al ADN indican que los genes homeóticos serian factores de transcripción. Esto es, las proteínas homeóticas regularían la actividad de otros genes reconociendo determinadas secuencias de ADN de determinados genes y controlando su transcripción. Esta implicación ha sido comprobada ya de muchas formas; se ha demostrado que las proteínas homeóticas están en el núcleo celular, que reconocen y se unen a determinadas secuencias de DNA, que activan transcripción en ensayos de transfección, etc. 2) La presencia de secuencias casi idénticas en varios genes adyacentes sugiere de forma muy rotunda que los genes homeóticos tienen un origen evolutivo común: todos derivan de un gen homeótico ancestral. Esto apoyaba firmemente la an- 
terior sugerencia de Ed Lewis basada en la localización cromosómica y en la formación de dupletes en los cromosomas politénicos.

Hubo, además otra consecuencia de índole práctico que se detalla a continuación, y que resultó ser de gran transcendencia.

\section{Genes homeóticos en otras especies. Conservación del complejo homeótico}

La identificación de genes homeóticos en otras especies, sobre todo en vertebrados, estaba dificultado por el escaso desarrollo relativo de las tecnologías genéticas y de análisis funcional. Era cuestionable que genes homeóticos como los descritos para Drosophila existieran en estas especies, y si así fuera, que tuvieran una función similar.

El descubrimiento de la homeobox como marcador molecular de los genes homeóticos permitió la búsqueda de estos genes en especies como la humana en las que seria muy difícil identificarlos por métodos genéticos convencionales. Sin embargo, las técnicas moleculares modernas permiten un aproximación diferente ya que las secuencias de homeobox de Drosophila se pueden utilizar para buscar en otros genomas, de ratón, humanos, etc. la presencia de secuencias parecidas.

Este tipo de análisis inmediatamente permitió demostrar que la secuencia homeobox existe en diversas especies de vertebrados, así como en especies representativas de todos los grupos animales existentes. La homeobox resultó ser una secuencia universal de los organismos multicelulares. Además, se pudo determinar que los genes de vertebrados con homeobox tenían otras secuencias en común con los genes de Drosophila y que además existían clases de homeobox similares a los de Drosophila. Así, en el ratón existía un gen con homeobox como la de Antennapedia, otro con homología con la de labial otro con Abdominal-B, etc. Se definieron así los genes ortólogos de ratón (que son además prácticamente idénticos a los humanos). Es decir en vertebrados existían genes muy parecidos a los de Drosophila, que además están agrupados en clases similares.

El siguiente descubrimiento, y quizás el más significativo, fué que los genes homeóticos de vertebrados también están formando un complejo de genes adyacentes y que el orden relativo de ellos es el mismo que el de Drosophila. La implicación de esta observación es que lo que se ha conservado en la evolución no es simplemente la homeobox o algún gen homeótico, sino el complejo Hox como un todo, su organización interna y el orden de los diferentes genes. La diferencia mayor 
entre insectos y vertebrados es que en estos se ha cuadruplicado el complejo, situación que aparentemente es única para este grupo animal ya que no se ha observado en ningún otro grupo. Además, en amphioxus, que se puede considerar como un vertebrado primitivo, solamente se observa una dosis del complejo. El significado funcional de esta cuadruplicación aún no ha sido establecido.

El estudio de los genes Hox en muchas especies diferentes de los diversos grupos animales ha establecido que el complejo homeótico es una característica universal de los animales pluricelulares. El registro fósil revela que los diferentes grupos sistemáticos o phila en los que se ha demostrado la existencia del complejo Hox existían ya hace unos 540 millones de años durante el Cámbrico inferior. Justamente es este periodo cuando tuvo lugar la aparición repentina de todos los phila del Reino Animal. La creencia general hoy dia es que existe una estrecha relación causal entre ambos fenómenos, la explosión del Cambrico y la aparición del complejo Hox. Seguramente la gran diversificación evolutiva que dió lugar a todos los grupos animales existentes fué debida a la creación de un sistema genético generador de diversidad morfológica.

\section{Conservación de la función homeótica en el Reino Animal}

Puesto que en Drosophila la función del complejo Hox es la de generar la diversidad morfológica a lo largo del eje anteroposterior, es de suponer que los Hox del resto de los organismos tengan una función parecida. La demostración de que las propiedades funcionales de los Hox son también comunes para insectos y vertebrados ha sido mas complicada debido a las dificultades del análisis genético en vertebrados y sobre todo al hecho de que existan cuatro copias de complejo Hox por genoma haploide. Esto plantea un problema de análisis genetico de dificil solución ya que la misma funcion puede estar codificada de forma mas o menos redundante por varios genes. Si por ejemplo se induce una mutación en el gen Hoxa8 (homólogo de Ultrabithorax) de ratón, aun quedan las formas normales de los los paralogos (los homólogos presentes en las restantes copias) Hab8, Hoxc8 y Hoxd8 los cuales pueden sustituir en parte al menos la función perdida en Hoxa8. El resultado es que la mutaciones individuales en ratón frecuentemente no tienen fenotipo, o tienen un fenotipo muy debil, lo que dificulta el análisis funcional. La generación de ratones conteniendo mutaciones para todos los genes parálogos y en los que por lo tanto 
no es posible la redundancia funcional, es una posibilidad que se está utilizando en la actualidad. A pesar de estas limitaciones, las técnicas de «knock out», nombre con el que se conocen los métodos de inducir mutaciones dirigidas en el ratón, ya han proporcionado datos que indican que el modo de acción y la función de los genes Hox de vertebrados son similares a los de Drosophila.

Además, hay otros tipos de evidencia que indican que muchas de las características funcionales de los genes Hox se han conservado durante la evolución del Reino Animal. Un ejemplo es la propiedad definida como colinearidad, la correspondencia que existe entre la posición de los diversos genes en el complejo y la expresión de esos mismos genes en el cuerpo: el orden de los genes en el complejo se correlaciona con el orden de expresión a lo largo del eje antero-posterior del cuerpo. El significado funcional de esta propiedad no esta esclarecido, pero es común a nemátodos, insectos y vertebrados y por lo tanto se supone que tiene que tener algún tipo de ventaja selectiva, ya que parece ser que es consustancial a la propia estructura del complejo Hox.

Una demostración más directa de la conservación funcional del complejo Hox es el hecho de que se pueden reemplazar genes de una especie por los de otra y realizan en la especie huésped una función similar a la del gen endógeno. Un ejemplo es el gen Antennapedia de Drosophila, responsable del desarrollo de las patas. Si este gen se expresa en la antena esta se transforma en una pata. En el ratón el gen homologo de Antennapedia es Hoxb4, y cuando Hoxb4 se introduce en Drosophila y se expresa en la antena, esta se transforma en una pata de mosca.

Otro ejemplo es el gen $A b d-B$ de Drosophila es el responsable de la diferenciación, entre otras estructuras, de los llamados filzkorpers, órganos relacionados con la respiración de las larvas y localizados al final de las traqueas. Si este gen no funciona debido a una mutación que lo inactiva, no se producen filzkorpers. En nuestro laboratorio hemos llevado a cabo experimentos en los que a una larva mutante para $A b d-B$ se le ha introducido el gen Hoxd11 de ratón y se le ha hecho expresar en la región posterior del cuerpo. Esta larvas diferencian filzskorpers muy parecidos a los normales, indicando que el gen de ratón sustituye eficientemente al de Drosophila.

Estos ejemplos de sustitución ilustran con claridad el papel de estos genes Hox. Como genes reguladores que son, controlan transcripcionalmente la función de otros genes subsidiarios que son los que realizan las funciones concretas para producir una pata o un filzskorper. Esta 
función de control la realizan de forma parecida en todas las especies a base de reconocer determinadas secuencias de ADN comunes a los genes subsidiarios y unirse a ellas. Los genes subsidiarios son específicos de especie, pero la estrategia general es común y los genes Hox que la controlan también, por lo que la cascada efectora se puede desencadenar por genes Hox de especies muy alejadas filogenéticamente. Lo que estos experimentos indican es que los procesos generales para organizar los patrones morfológicos son comunes a todo el Reino Animal.

\section{Otros genes homeóticos que no pertenecen al complejo Hox}

La búsqueda de genes con homeobox o secuencias similares ha conducido al aislamiento en muchas especies animales y en la especie humana de un numero relativamente grande de genes que contienen estas secuencias pero que no están ligados al complejo Hox. El proyecto Genoma de Drosophila ha demostrado le existencia en esta especie de mas de 100 secuencias homeobox, de los cuales al menos 25 representan funciones biológicas concretas ya que se han identificado mutaciones en ellos.

La historia evolutiva de cada uno de estos genes no está resuelta, se piensa que en algunos casos son genes del complejo homeótico original que se separaron mediante reordenamientos cromosómicos. Sin embargo, lo que está claro es que la homeobox es evolutivamente anterior al complejo Hox y que este apareció debido a la duplicación en tandem de un único gen con homeobox. El resto de los genes con homeobox habrían seguido una evolución independiente. Como ha propuesto Burglin (1995) hubo un gen con una homeobox ascentral, urohomeobox, del que derivarían todos los demás. Una característica muy importante de estos genes es que aunque no tienen una función tan general como los genes Hox prácticamente en todos los casos son responsables de procesos de especificación del desarrollo de órganos o tejidos. Parece ser que el tipo de unión al $\mathrm{ADN}$ que produce el homeodominio hace que estas proteínas sean particularmente apropiadas para regular los procesos de desarrollo. Los ejemplos que se detallan a continuación ilustran el importante papel que tienen estos genes.

\section{Genes con homeobox y la formación de apéndices}

Los apéndices de insectos, como las extremidades de vertebrados, son estructuras especiales, generalmente relacionados con el movimien- 
to, locomoción, vuelo etc. y que surgen a partir del la parte principal del cuerpo o tronco. Los genes encargados del desarrollo de los apéndices de Drosophila, alas, patas y antenas se conocen con bastante detalle.

En el caso de los apéndices ventrales, patas y antenas, el papel fundamental lo ejerce Distal-less. Este gen se activa en durante el desarrollo embrionario precisamente en las células que han de formar los apendices ventrales y partir de este momento establece en esas células el programa genético característico. Para distinguir entre los diversos apéndices ventrales, pata, antena o analia Distal-less actua en combinación con el gen Hox correspondiente. Quizás la forma mas directa de demostrar el papel de este gen en el desarrollo sean los experimentos de expresión ectópica, en los que se manipula la expresión del gen activándolo en zonas del organismo donde normalmente no funciona. Se ha demostrado que si por ejemplo Distal-less se expresa en el ala, esta se transforma en pata, mientras que si se expresa en el ojo este se transforma en antena. Estos experimentos demuestran claramente el importante papel regulador del gen, ya que su producto es capaz por si solo de generar un apéndice supernumerario.

El gen Distal-less está presente en todas las especies analizadas del Reino Animal y en todos los casos se expresa especificamente en las celulas que forman apéndices, lo cual sugiere que ejerce una función similar o idéntica en al menos todos los artrópodos. Aunque el análisis funcional de los homologos in vertebrados está menos avanzado, su expresión en el borde de crecimiento de las extremidades de ratón claramente sugiere un papel en la especificación de estas estructuras.

La conservación funcional de la funcion homeótica en los mecanismos de formación de apéndices se demuestra también apterous, un gen también con homeobox, que es esencial para formar el ala de Drosophila. La mutaciones que inactivan el gen producen moscas sin alas. Este gen también existe en la especie humana aunque su función no se conoce dadas las dificultades que se dan para el análisis funcional. Sin embargo, el gen humano homólogo al de mosca, llamado $L h x$, ha sido clonado y es posible introducirlo en Drosophila. Hemos demostrado (en colaboración con los grupos de Juan Botas y el de Izpizua Belmonte) que el gen humano es capaz de rescatar el fenotipo mutante de moscas deficiente para su propio gen endógeno. Este ejemplo ilustra con claridad el grado de conservación de los sistemas genéticos de diseño en todo el Reino Animal; los genes de moscas y humanos han estado separados durante 540 millones de años y aun así son intercambiables. 


\section{La formación del ojo}

Los ojos, órganos desarrollados para recibir e interpretar la señales luminosas, son una de las estructuras más fascinantes producidos por la evolución. El mismo Darwin argumentaba que encontraba serias dificultades para explicar mediante selección natural la formación de estructuras tan delicadas y complejas como son los ojos de las diversas especies. Sobre todo porque se suponía que los ojos habían aparecido de forma independiente muchas veces durante la evolución. Se consideraba que el ojo simple de un vertebrado es muy diferente del ojo compuesto de un insecto, formado por cientos de ommatidias.

En 1991, el grupo de Walter Gehring en Basilea clonó y secuenció en Drosophila un gen, llamado eyeless, cuya función es esencial para que se forme el ojo de la mosca; las mutaciones que inactivan este gen no poseen ojos. Se encontró en primer lugar que posee una homeobox, sugiriendo que eyeless tiene un papel regulador de alto rango similar al que tienen los otros genes homeóticos tratados anteriormente. La búsqueda de secuencias parecidas en otras especies indicó la existencia de un gen, llamado Pax6, con alta homología tanto en ratón como en humanos. Además en este caso se conocían mutaciones en los genes Pax6 de ratón y humanos. Estas mutaciones, small eye en ratón y Aniridia en humanos, también dan lugar a falta de ojos. Estos resultados sugerían que el mismo gen se encarga de especificar el desarrollo de los ojos en insectos, ratones y humanos, en contra de la idea de que los ojos tienen un origen evolutivo diferente en los diversos grupos animales. Pero quizás la demostración mas espectacular de la homología de estos genes es la realizada por el grupo de Gehring de que el gen de ratón es capaz de reemplazar al gen de mosca y generar un ojo en la mosca. Estos experimentos consistieron en introducir el gen de ratón en Drosophila y activarlo en diversas regiones del cuerpo tales como patas, alas, antenas, etc. El resultado fue que aparecen ojos ectópicos en todas estas estructuras.

Estos experimentos revelan una homología extraordinaria en lo que respecta al sistema genético que forma el ojo. Un ratón no tiene ojos de mosca, los cuales se forman por la contribución de varios cientos de genes específicos que no existen en el ratón. El papel del gen eyeless es precisamente activar toda esa maquinaria genética. El hecho de que el gen $\operatorname{Pax} 6$ de ratón sea capaz de activar esta maquinaria indica que lo que está conservado en insectos y vertebrados es la programación genética general de la formación del ojo, su diseño genético. Durante los últimos años varios grupos de investigadores han buscado homólogos 
de Pax6 en todo el Reino Animal, habiéndose encontrado en prácticamente todas las especies estudiadas. El análisis de su expresión en el cuerpo indica que en todos los casos bien caracterizados está asociado a los aparatos visuales y mecanismos receptores de luz.

\section{Conclusiones generales}

Como se exponía en la introducción, quizás el descubrimiento mas significativo de la Biología Molecular es el de la universalidad de los fenómenos biológicos básicos; la naturaleza de la información genética, su expresión y replicación, el metabolismo celular etc. Esta universalidad tiene sus raíces en el propio mecanismo de la evolución que tiende a fijar la aparición de nuevas funciones que confieren ventaja selectiva a los grupos que las poseen. En lo que respecta al diseño del cuerpo de los organismos multicelulares, la diversificación morfológica del cuerpo en diversos componentes con distintas funciones especializadas seguramente representó un gran ventaja selectiva para los grupos animales que los desarrollaron, ya que permitió una división de trabajo que sin duda influyó en su capacidad de adaptación y supervivencia. Piénsese en la ventaja evolutiva que supuso la aparición de apéndices para locomoción, órganos de visión o el desarrollo del cerebro en la parte anterior del cuerpo, la dirección de movimiento, como órgano receptor señales externas y coordinador de muchas de las actividades internas.

Toda esta diversificación proviene en última instancia de la función de los genes con la secuencia homeobox, bien en forma del complejo Hox o en forma de genes individuales como Distal-less, apterous o eyeless, por citar solamente algunos casos. La homeobox surgió hace unos 1000 millones de años, y hace unos 540 millones uno de los varios genes con homeobox que deberían existir entonces sufrió una serie de duplicaciones en tandem (mecanismo por otro lado muy frecuente en la evolución) que dió lugar a un conjunto de genes similares y orientados de la misma forma en el cromosoma. Este fue el origen del complejo homeótico. Por un procedimiento que aun está por dilucidar, la disposición de los genes dentro del complejo se traduce en una lectura posicional de su propia activación en los ejes espaciales del cuerpo. Este fascinante proceso de colinearidad está presente en todas las especies estudiadas del Reino Animal y es la clave de la diversificación morfológica en el eje antero-posterior del cuerpo. Esto es debido a que siendo los genes homeóticos reguladores de otros genes subsidiarios 
que se ocupan de cada uno de los aspectos concretos de la morfogénesis, la función espacialmente localizada de los genes homeóticos da lugar a la activación espacialmente regulada de los genes subsidiarios, lo que conduce a la formación de estructuras diferentes a lo largo del eje antero-posterior. Las posibilidades evolutivas que ofrecía este dispositivo eran tales que en un tiempo evolutivo muy pequeño (se calcula unos 25 millones de años) dió lugar a la famosa «explosión del Cámbrico», que detectaron los paleontólogos: la repentina aparición durante esta época de todos los grupos animales tal como los conocemos en al actualidad. La tremenda diversificación morfológica que se observa en los millones de especies que pueblan el planeta resulta en gran medida de la aparición de esta cadena de 6-8 genes que originalmente formaron el complejo homeótico ancestral. 